\title{
PREDICTING HUNGARIAN SOUND DURATIONS FOR CONTINUOUS SPEECH*
}

\author{
GÁBOR OLASZY
}

\begin{abstract}
Direct measurements show that a number of factors influence the final value of sound durations in continuous speech. On the segmental level it is mainly the articulatory movements that determine important influence factors, while on the suprasegmental level accent, syllabic stress, within-word position, the preceding and following syllables and finally utterance position may have an influence on final sound durations. So the problem of how to predict sound durations can be described with a multivariable function in which the effect of the variables cannot be easily defined with good accuracy. It is difficult to separate the effects of certain functions, i.e., it is difficult to model this function, making direct measurements on the speech signal.

A model has been constructed and realized in which three well-defined levels are working separately. In the first one (this is the segmental level) the separation of the effect of articulation from other factors is solved. The second and third levels relate to the suprasegmental level of speech.
\end{abstract}

\section{Introduction}

During speech production the articulatory movements form the frequency and time structure of the speech signal. It is also well known that articulation has an influence on sound duration. Different methods may be used to describe this effect. The use of an articulatory model is described by Shiga et al. (1998) where four time-variable articulatory parameters represent the conditions of articulatory organs whose physical restrictions seem to significantly influence segmental duration.

Measurements showed that, beside the effect of articulatory movements, other factors also influence the value of the duration of a sound. Van Santen (1992) points out that at least eight factors matter in this process: accent,

* This research was partly supported by the Hungarian Research Fund (OTKA T 037288). The algorithms for the synthesis supported perceptual tests and for the distribution measurements were programmed at the Budapest University of Technology and Economics, Department of Telecommunications and Telematics by Péter Olaszi and Géza Kiss.

1216-8076/02/\$ 5.00 (c) 2002 Akadémiai Kiadó, Budapest 
syllabic stress, vowel type, prevocalic and postvocalic consonants, within-word position, the preceding and following syllables and finally utterance position.

Earlier measurements of sound durations in Hungarian concern both the inherent time structure of sounds (transient phases, structure of consonants, VOT, etc.) and also the overall duration of sounds. The latter has been examined by Magdics (1966), Kassai (1979), and most recently by Kovács (2002). The inherent time structure of every Hungarian sound has been examined by Olaszy (1991). The first synthesis-controlled measurements for the examination of the structure and duration of Hungarian consonants were made by Olaszy (1985). All four authors gave the results mainly in the form of mean values and main tendencies. These data are somewhat different from what is required for the construction of a duration model. For example, textto-speech (TTS) conversion requires an adequate duration model for the given language. The construction of that model is complicated by the multitude of phenomena which affect durations in speech (O'Shaughnessy 1981). For this reason researchers try to separate certain factors during their investigations and try to define controlled environments (limited number of words, using nonsense items, placing words or syllables in frame sentences etc.) in which only one changing factor is present at a time. For example, in a study of French vowel and consonant durations, O'Shaughnessy (1981) limited the investigation to stressed syllables in words. Van Santen (1992) used specially created sentence pairs for the investigation of contextual effects on English vowel durations.

The model proposed in this paper gives us the possibility to separate the various effects that influence the creation of sound durations. First, the influence of articulation is taken into consideration (segmental level of speech), secondly, the influence of other factors is discussed. The results of the segmental level part are expressed by specific, articulation-governed sound durations (the duration of every sound as a function of adjacent sounds for continuous speech). These specific duration values are used as a basis for further (word and sentence level) calculations. Thus the prediction of speech sound durations can be performed by the model for the sounds of any text without direct measurements.

\subsection{State of the art}

The modelling of sound durations became increasingly important due to the fast development of speech technology (text-to-speech conversion, speech recognition) in the past few decades. Two main approaches were proposed: 
rule-governed and statistical systems. In rule-governed approaches the researchers try to characterize the whole complex process with rules (basically on the linguistic level). The duration of a sound is characterised here by an intrinsic value. In the calculation of the final duration, various phenomena (mainly defined from syntactic information) are taken into consideration and applied on the intrinsic durations.

The statistical approach, on the other hand, uses the results of statistical measurements to predict sound duration. It is difficult to separate definitely the rule-based and the statistical approach. For example, the MITalk TTS system (Allen et al. 1987) is regarded by Zellner (1994) as a statistical system, while van Santen (1998) mentions it as a purely rule-based solution. The MITalk system seems to involve both, because this model is built around average duration, i.e., durations for individual phonemes which represent the result of statistical measurements. The final duration is then calculated after taking the position within a paragraph, the semantic novelty, the phrase structure, etc. into consideration.

In a more recent approach, Campbell (1992) proposed another type of determination of sound durations. According to this, first the higher level syllable durations have to be calculated to reflect the rhythmic and structural organisation of the utterance and the durations of the sounds in the syllable are calculated from the syllable durations.

One common feature of all these approaches is that the duration data and rules are derived from natural speech material. The disadvantage of these methods is that the measured duration values contain the effect of more than one feature in many cases. Moreover, the generality of the results may be restricted by the influence of individual pronunciation (van Santen 1998).

\subsection{Hypothesis}

The hypothesis was that the surface level final durations can be built from low level basic structures. The concept follows the theoretical separation of speech into segmental and suprasegmental levels. Segmental level durations represent the basis (speech without prosody but having the correct specific duration values of the sounds, the distribution of durations, the correct, language specific timing ratios among speech sounds). At this level only the articulation has an effect on sound durations. We assume that data on this level can give the basis for the further calculations (modifications of the specific durations) which are determined on the suprasegmental (surface) level. 


\section{The method used}

In this paper we describe an inverse (bottom-up) method to define the final, surface level sound durations. Sound durations are determined in three steps in this model.

1. The most important part of the whole procedure is the indirect measuring method that is applied to determine the specific durations: $(t)$ spec. Their value varies only as a function of articulation. The indirect measuring method means that the duration values are not defined by measuring the sound durations in natural speech, but by using the combination of segmental level speech synthesis and perceptual evaluations. Thus the specific sound durations characteristic of continuous speech (taking the effects of the continuous serial articulation process into consideration) will be determined in milliseconds (for a certain articulation rate).

2. The second step is based on the results of step (1) and the modification factors defined are derived from the words as building units of speech. Word level modification rules have been formulated which showed to what extent the specific duration of the sounds has to be lengthened or shortened within the word (in continuous speech). The result of this step is a modification factor (M1) for every sound of the word. M1 is defined by the following variables: the length of the word and the sound map of the word (which sounds and sound combinations are in the word, and what is the sound order). All sounds of the word are supplied with M1. The series of these numbers is called word level duration map.

3. The third (suprasegmental) level of the model represents the final adjustment of the sound durations. The second modification factor (M2) is defined by sentence level rules (modality, phrase structure, prominence etc.).

The final sound durations (individually for every sound of the utterance as a function of the adjacent sounds) are then calculated in the following way:

$$
\text { (t) final }=(t) \operatorname{spec} \times \mathrm{M} 1 \times \mathrm{M} 2
$$

As a result of the three steps the final sound durations of every sound in the utterance will be defined. 
The experimental setup for getting specific durations was organized around a segmental level TTS synthesizer, a perceptual evaluation procedure and a sound duration modifier (Figure 1).

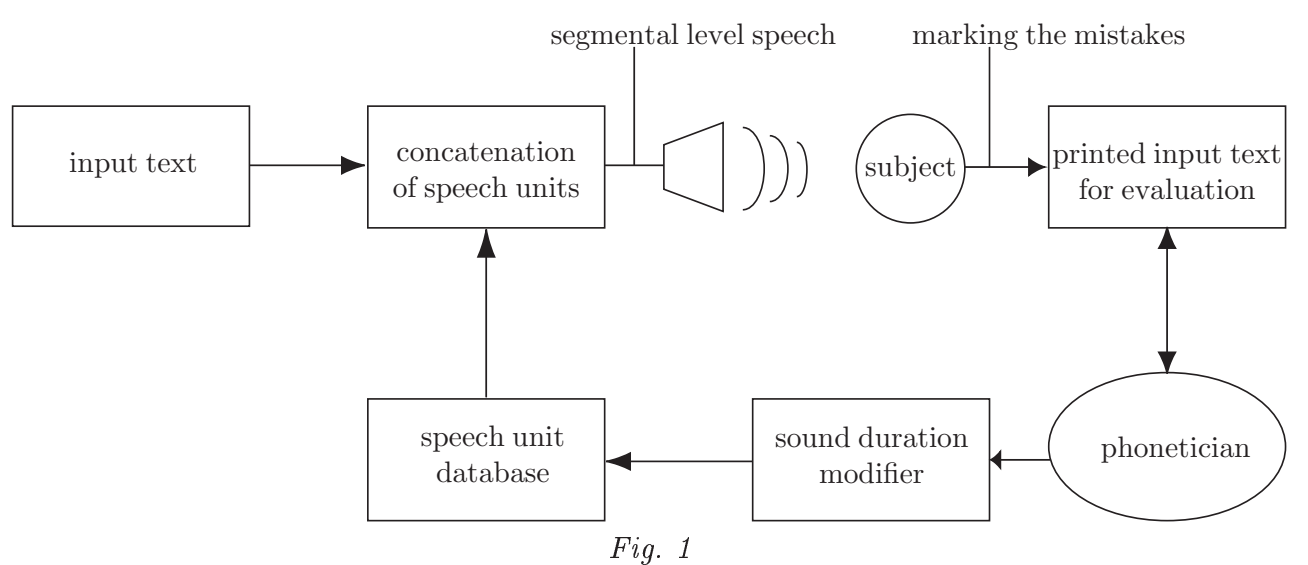

The test environment for the adjustment of specific sound durations

The TTS synthesizer consists of a speech unit database (waveform elements derived from human pronunciation) a concatenation module, a graphemesound converter and a sound duration modifier. This synthesizer produced the speech (withouth melody and accent) for the perceptual evaluation. The design and realization of this synthesizer was one of the most complicated elements in setting up the test environment. The steps of realization were as follows: (a) determination of the speech sound set for the TTS conversion; (b) definition of the form of the elements of the speech unit database for concatenation; (c) designing the text corpus for the creation of the elements of the speech unit database; (d) the realization of the speech unit database.

\subsection{Speech sound set and its representation in the experiment}

The goal of the experiment was to measure the duration of the 9 basic vowels (7 short ones plus long [a: ] and [e:]) and the 23 short consonants of Hungarian (Table 1, Table 2). The symbols of the third rows of the tables represent the appropriate character for the given sound in the representation of computer programs. These characters will be used in computer generated tables and figures. The characters of the third rows will be written between brackets like (a), (A), (u), (U) when referring to a Hungarian speech sound. The phonetic symbols of sounds will be written as: [э], [a: ], [o], etc. 
Table 1

The basic Hungarian vowels used in the experiment

\begin{tabular}{|l|c|c|c|c|c|c|c|c|c|}
\hline IPA symbol & a: & o & o & u & y & i & e: & $\varnothing$ & $\varepsilon$ \\
\hline written form & á & a & o & u & $\ddot{u}$ & i & é & ö & e \\
\hline symbol in this experiment & A & a & o & u & U & i & E & O & e \\
\hline
\end{tabular}

Table 2

The basic Hungarian consonants used in the experiment

\begin{tabular}{|l|c|c|c|c|c|c|c|c|c|c|c|c|c|c|c|c|c|c|c|c|c|c|c|}
\hline IPA symbol & b & p & d & t & g & k & f & c & m & n & n & j & h & v & f & z & s & ts & 3 & f & t & l & r \\
\hline written form & b & p & d & t & g & k & gy & ty & m & n & ny & j & h & v & f & z & sz & c & zs & s & cs & l & r \\
\hline $\begin{array}{l}\text { symbol in this } \\
\text { experiment }\end{array}$ & b & p & d & t & g & k & G & T & m & n & N & j & h & v & f & z & s & c & Z & S & C & l & r \\
\hline
\end{tabular}

\subsection{Definition and realisation of the speech unit inventory for synthesis}

The goal of the definition of the form of speech units was to produce good quality speech (close to natural voice timbre) by the synthesizer. Thus the sound quality will influence the listeners in their duration evaluation to a lesser extent. As the ultimate goal was to define the duration of a sound taking the effect of the adjacent sounds into account, theoretically $\mathrm{CVC}, \mathrm{VCV}$, CCV, VCC, VVC and CVV elements could have been used as building units. As perceptual experiments showed that listeners are more sensitive to duration failures in vowels than in consonants (Kato et al. 1998), we treated vowel duration as the most important kind of data, especially in CVC combinations. Our latest measurements showed that this combination type occurs most frequently in Hungarian (80\% of the triphone units are of a CVC structure, measured in a corpus of 2 million different word forms). The duration of the vowel can be determined the most correctly if the vowel is treated during the synthesis as an individual element influenced only by the actual surrounding consonants, i.e., every vowel in every $\mathrm{CVC}$ combination has its own specific duration and this duration value represents the duration of the vowel only in the given $\mathbf{C V C}$ combination. If we take into account the fact that the given vowel may be preceded by any consonant and may be followed also by any one, theoretically the effect of articulation of adjacent consonants on the duration of any vowel can be defined by four cases as indicated in Table 3.

The final decision was to use triphone CVC elements in the speech unit inventory to ensure the possibility of most precise adjustment for vowels in 
Table 3

The theoretical effect of consonants on vowel duration in CVC sequences

\begin{tabular}{|c|c|c|c|c|}
\hline \multicolumn{2}{|c|}{ PRECEDING CONSONANT } & \multicolumn{2}{|c|}{ FOLLOWING CONSONANT } & \multirow[b]{2}{*}{ THE FINAL DURATION OF THE VOWEL } \\
\hline $\begin{array}{l}\text { lengthening } \\
\text { the vowel }\end{array}$ & $\begin{array}{l}\text { shortening } \\
\text { the vowel }\end{array}$ & $\begin{array}{l}\text { lengthening } \\
\text { the vowel }\end{array}$ & $\begin{array}{l}\text { shortening } \\
\text { the vowel }\end{array}$ & \\
\hline+ & & + & & $\begin{array}{l}\text { lengthened } \\
\text { (doubled lengthening influence) }\end{array}$ \\
\hline+ & & & - & equalized (not changed) \\
\hline & - & & - & $\begin{array}{l}\text { shortened } \\
\text { (doubled shortening influence) }\end{array}$ \\
\hline & - & + & & equalized (not changed) \\
\hline
\end{tabular}

CVC combinations during the perceptual evaluations. This fact defined the final content of the speech unit database: vowels in CVC combinations were generated form CVC triphones, all other sound combinations were generated using the concatenation of $\mathrm{CV}, \mathrm{VC}, \mathrm{VV}$, and $\mathrm{CC}$ diphones. One triphone element contained two half consonants and the vowel between them. One diphone element contained two half speech sounds (e.g., a CV unit has the second part of the $\mathrm{C}$ and the first half of the $\mathrm{V}$ ). The speech unit database was planned to have $4761 \mathrm{CVC}$ triphones, $207 \mathrm{CV}, 207 \mathrm{VC}, 81 \mathrm{VV}$ and 529 $\mathrm{CC}$ diphones.

\subsection{The criteria for the creation of the speech unit database}

The elements of the speech unit database were created from human voice items. A text corpus had been designed which was read by a male announcer. Three aims were kept in mind when designing the text corpus: (a) to keep the correct formant structure in vowels (mainly in CV, VC and VV diphones; (b) to reduce the effect of suprasegmental factors (accent, rhythm, melody, etc.); and (c) to have controlling possibilities for keeping sound intensity close to a constant value during the recording.

To meet these requirements three-syllable meaningless text items were defined for the announcer.

An example of the meaningless text items containing the vowel (o) for CVC triphone units, where the vowel was preceded by the consonant [b] and followed by all consonants looked like this: aboba [jbobə], abopa [jbopo],

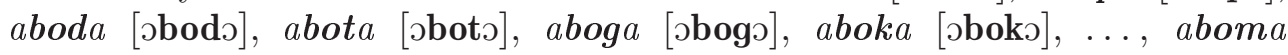
[jbomo], abona [əbono], etc. 
The text items for the production of the CV, VC and VV diphones were designed using a well known phonetic rule. The problem in diphone representation is that vowels are cut at their middle point. When generating a vowel in the synthesis process with the concatenation of two diphones, spectral discontinuities may occur in the formant structure of the vowel at the point of concatenation. This produces distortion. To reduce these distortions the formants of vowels were controlled by phonetic means to reach an optimal steady state position at the concatenation point for both $\mathrm{CV}$ and $\mathrm{VC}$ diphones. The $[\mathrm{k}]$ sound was used for this purpose because this sound is the most flexible as to its articulation and it does not influence the formant structure either of the preceding (in a VC combination) or of the following vowel (CV) very much. In items for $\mathrm{CV}$ diphones the $[\mathrm{k}]$ sound follows the vowel, i.e., the formants of the vowel will be close to the steady state values at the second half of the vowel where the cut will be done. Examples of the meaningless text items containing CV diphone elements are: aboka [əboko], apoka [əpoko],

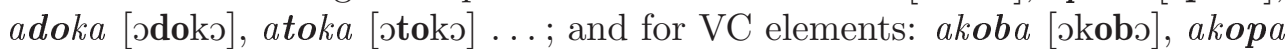
[okopo], akoda [okodo], akota [okoto]. In items for $\mathrm{VC}$ diphones the [k] sound precedes the vowel, i.e., the formants of the vowel will be close to the steady state values in the first half of the vowel where the cut will be done. Thus it can be assumed that the discontinuity in formants will be low and by concatenating these diphones, the formant frequencies at the concatenation point will be close to each other, therefore spectral distortion will be minimal.

For the production of $\mathrm{CC}$ diphones, words containing the given sequence were mostly given in the text list.

The structure of the text corpus described above solved two other problems, too. It was possible not to have accent on the triphone or on the diphone element (in Hungarian the accent is on the first syllable of the pronounced word) and, with the use of [o] in the first and in the last syllable, the sound intensity level became controllable (the demand was to keep it constant as far as it can be during the recording).

\subsection{Realization of the speech unit database}

The text material was read by a trained male speaker in a monotonous style (keeping the fundamental frequency as constant as it was possible) but with normal speech rate. The digital representation $(22 \mathrm{kHz}, 16 \mathrm{bit})$ of the wave form was labelled on sound boundaries (semi-automatically) and pitch synchronisation markers were placed too (semi-automatically). It is obvious that the correctness of any sound duration measurement strongly depends on the 
definition of sound boundaries in the measurable waveform. In our case a phonetician labelled the sound boundaries manually (with visual and auditive control). Visual observations concerned the waveform and the intensity curve of the signal. In some special cases a spectrographic analysis was also used to define the sound boundary. The flexible "play the sound window" option made the auditive control more effective, i.e., the acoustic change in the sound could be heard by adding, step by step, one more period to the previously selected and played part of the window. All these supports were given by the Hungarian Profivox Development System (PDS) software tool (Olaszy et al. 2001). For vowels in CVC combinations the onset and offset were determined mostly very correctly (consonantal aspiration was not involved). In VV combinations, the auditive examination gave the most important help to determine the boundary. In the case of sonorant-vowel combinations, the analysis of the intensity curve and the auditive examination gave the desired result.

The speech unit database was created by a semi-automatic method. The cut points for CVC elements were defined at the middle of the consonants, and for diphone elements at the middle of the sounds. This database contained individual vowel durations for every CVC combination type and created durations for all other sounds in all combinations. Created duration means that the duration of the sound will be defined by the two diphones used actually.

\subsection{The perceptual evaluation}

The determination of specific durations was carried out by a multi-step, longlasting perceptual evaluation (Figure 1). It represented a closed circuit sound duration evaluation and correction procedure. The TTS produced the voice (without suprasegmental structure) from the input text. Two types of input text were used: a basic and a general text material. The basic one consisted of 1200 sentences, (5-10 words in a sentence). The general one contained texts from newspapers, books and scientific articles. The printed form of all these text materials served for marking the results of the duration evaluation.

Four subjects of normal hearing (one female and three males, ages between 30 and 50) completed the whole test. The whole perceptual evaluation and duration correction procedure lasted for eight months. The listening was arranged always for one subject at a time. One listening session lasted for max. 30 minutes, and about 50 sentences were evaluated. The articulation speed of the synthetic speech was 12-13 sounds/s, this corresponds to a medium speaking rate in Hungarian (Kovács 2002).

The steps of the perceptual evaluation were as follow: 
1. The subject was asked to listen to the synthesised text sentence by sentence. He/she had to evaluate the duration of the sounds of the given sentence, and to mark with the predefined marker on the printed text those sounds the duration of which was heard to be too long $(-)$ or too short $(*)$. Using a repeat function the previous sentence could be listened to several times if required. An evaluated sentence showed, for example, the following picture:

(1) A tervezett tárgyalás után levelet írok a külföldi partnernek. 'After the planned discussion I will write a letter to the foreign partner.

The markers in the example show that there was one too short part at the beginning of the first word, one longer vowel was found in the second word, and so on.

2. A phonetician took part in the test, too. He controlled the marked judgments of the subjects. In cases of 3 or 4 identical opinions for the same sound he accepted the opinion and made the lengthening or shortening according to his own decision and perceptual judgement. In cases of only 2 corresponding opinions he did not make any correction. The duration change was set in the given part of the triphone or diphone in question. Thus the speech unit database contained more and more closely correct durations. After making all corrections the listeners were asked (2-3 weeks later) to make the evaluation (points 1 and 2) once more for the whole text. A special, sound duration modifier program (Olaszy-Olaszi 1998) helped the phonetician to make the corrections.

Going ahead in the evaluation procedure, more and more sounds reached their correct, segmental level, specific duration characteristic for continuous speech. The subjects were able to mark the mistakes in durations more and more precisely. Already the experiments of Huggins (1972) had shown that listeners can perceive very small changes in duration. In this experiment the sensitivity of the listeners reached the $10 \mathrm{~ms}$ value in the final phase. The test procedure was done altogether four times with the four subjects.

3. After this phase, ordinary texts (from newspapers, articles, weather forecast, etc.) were synthesised by the system (without prosody parameters) and sound duration values were tested the same way as in points 1 and 2 . Such texts automatically contain the language specific 
occurrence ratios of segmental units. So, the duration of the most frequent sounds in the most frequent sound combinations was evaluated and corrected (if needed) once again.

4. After the whole procedure the segmental level speech (produced by the final speech unit database) was very balanced from the point of view of correct sound duration values in continuous speech. The produced synthetic speech (without prosody) was fluent, and clearly understandable. This database was then declared to be the reference database that incorporates the specific sound duration values (for all sound combinations) involving the influence of articulation on duration. These duration values are characteristic of Hungarian speech production and can serve as a stable basis for further calculation of final durations on the suprasegmental level.

\section{Results and criticism}

The goal of the whole procedure was not only to determine the segmental level sound durations, but also to prove the correctness of this new indirect procedure and the results obtained. Therefore, besides the definition of specific sound durations, distribution measurements have been performed to study the data produced by the first level of the model. The aim of these distribution measurements was to get an overview (on data level) about the behaviour of specific sound durations in different sound combinations. The data have been compared with earlier results (derived from direct duration measurements by Kassai (1979) and Magdics (1966)). It was assumed that, if these new results correlate with earlier results, the method presented can be accepted as an objective procedure for the definition of the segmental level, specific, articulation-governed sound duration structure of a language.

\subsection{Vowels in $\mathrm{C} V \mathrm{C}$ combinations}

The results contain duration values for nine vowels in 4761 different combinations. The data are presented in the form of matrices for every vowel. A sample matrix for the sound (o) is given in Table 4. The table shows the specific duration values of (o) in all $\mathrm{CVC}$ combinations. The leftmost column of the matrix represents the preceding $\mathrm{C}$, the top row the following $\mathrm{C}$. The target vowel (o) is shown at the upper left corner of the matrix. So if we want to get the specific duration of (o) in the sequence boldog [boldog] 'happy' we 
take the row of (b) and the column of (1). The result is $84 \mathrm{~ms}$ for the given articulation rate. For the second (o) we take the row of (d) and the column of $(\mathrm{g})$. The result is $91 \mathrm{~ms}$.

Table 4

The specific durations of (o) in CVC combinations in ms for continuous speech

\begin{tabular}{|c|c|c|c|c|c|c|c|c|c|c|c|c|c|c|c|c|c|c|c|c|c|c|c|}
\hline o & b & $\mathbf{p}$ & d & $\mathbf{t}$ & g & $\mathbf{k}$ & $\mathbf{G}$ & $\mathbf{T}$ & $\mathbf{m}$ & $\mathbf{n}$ & $\overline{\mathbf{N}}$ & $\mathbf{j}$ & h & $\overline{\mathbf{V}}$ & f & $\mathbf{z}$ & $\mathbf{s}$ & c & $\bar{Z}$ & $\mathbf{S}$ & $\mathbf{C}$ & 1 & $\mathbf{r}$ \\
\hline$\overline{\mathbf{b}}$ & 88 & 93 & 84 & $\overline{95}$ & 93 & $\overline{90}$ & 93 & 103 & 83 & 84 & $\overline{94}$ & 95 & 95 & 85 & $\overline{94}$ & $\overline{93}$ & 0 & 94 & $\overline{94}$ & 85 & 83 & 84 & $\overline{94}$ \\
\hline $\mathbf{p}$ & 88 & 93 & 83 & 95 & 92 & 90 & 92 & 103 & 82 & 83 & 93 & 95 & 95 & 84 & 93 & 93 & 90 & 94 & 94 & 84 & 83 & 83 & 93 \\
\hline d & 86 & 91 & 82 & 93 & 91 & 88 & 91 & 101 & 81 & 81 & 92 & 93 & 93 & 83 & 91 & 91 & 88 & 92 & 92 & 83 & 81 & 82 & 92 \\
\hline $\mathbf{t}$ & 84 & 90 & 80 & 92 & 89 & 86 & 89 & 100 & 79 & 80 & 90 & 92 & 92 & 81 & 90 & 90 & 87 & 91 & 91 & 81 & 80 & 80 & 90 \\
\hline $\mathrm{g}$ & 87 & 92 & 83 & 94 & 92 & 89 & 92 & 102 & 82 & 82 & 93 & 94 & 94 & 84 & 92 & 92 & 89 & 93 & 93 & 84 & 82 & 83 & 93 \\
\hline $\mathbf{k}$ & 79 & 84 & 75 & 86 & 84 & 81 & 84 & 94 & 74 & 74 & 85 & 86 & 86 & 76 & 84 & 84 & 81 & 85 & 85 & 76 & 74 & 75 & 85 \\
\hline $\mathbf{G}$ & 90 & 95 & 85 & 97 & 94 & 92 & 94 & 105 & 84 & 85 & 95 & 97 & 97 & 86 & 95 & 95 & 92 & 96 & 96 & 86 & 85 & 85 & 95 \\
\hline $\mathbf{T}$ & 99 & 104 & 95 & 106 & 104 & 101 & 104 & 115 & 94 & 95 & 105 & 106 & 106 & 96 & 105 & 105 & 101 & 106 & 106 & 96 & 95 & 95 & 105 \\
\hline $\mathbf{m}$ & 79 & 85 & 75 & 87 & 84 & 81 & 84 & 95 & 74 & 75 & 85 & 86 & 86 & 76 & 85 & 85 & 81 & 86 & 86 & 76 & 75 & 75 & 85 \\
\hline $\mathbf{n}$ & 90 & 96 & 86 & 98 & 95 & 92 & 95 & 106 & 85 & 86 & 96 & 98 & 98 & 87 & 96 & 96 & 93 & 97 & 97 & 87 & 86 & 86 & 96 \\
\hline $\mathbf{N}$ & 94 & 99 & 90 & 101 & 99 & 96 & 99 & 109 & 89 & 90 & 100 & 101 & 101 & 91 & 100 & 99 & 96 & 100 & 100 & 91 & 89 & 90 & 100 \\
\hline $\mathbf{j}$ & 80 & 86 & 76 & 88 & 85 & 82 & 85 & 96 & 75 & 76 & 86 & 87 & 87 & 77 & 86 & 86 & 82 & 87 & 87 & 77 & 76 & 76 & 86 \\
\hline $\mathbf{h}$ & 90 & 96 & 86 & 98 & 95 & 92 & 95 & 106 & 85 & 86 & 96 & 98 & 98 & 87 & 96 & 96 & 93 & 97 & 97 & 87 & 86 & 86 & 96 \\
\hline $\mathbf{v}$ & 88 & 94 & 84 & 96 & 93 & 90 & 93 & 104 & 83 & 84 & 94 & 96 & 96 & 85 & 94 & 94 & 91 & 95 & 95 & 85 & 84 & 84 & 94 \\
\hline $\mathbf{f}$ & 80 & 86 & 76 & 88 & 85 & 82 & 85 & 96 & 75 & 76 & 86 & 88 & 88 & 77 & 86 & 86 & 83 & 87 & 87 & 77 & 76 & 76 & 86 \\
\hline $\mathbf{z}$ & 91 & 96 & 87 & 98 & 96 & 93 & 96 & 106 & 86 & 86 & 97 & 98 & 98 & 88 & 96 & 96 & 93 & 97 & 97 & 88 & 86 & 87 & 97 \\
\hline $\mathbf{s}$ & 87 & 92 & 83 & 94 & 92 & 89 & 92 & 103 & 82 & 83 & 93 & 94 & 94 & 84 & 93 & 93 & 89 & 94 & 94 & 84 & 83 & 83 & 93 \\
\hline c & 93 & 98 & 88 & 100 & 97 & 95 & 97 & 108 & 87 & 88 & 98 & 100 & 100 & 89 & 98 & 98 & 95 & 99 & 99 & 89 & 88 & 88 & 98 \\
\hline $\mathbf{Z}$ & 87 & 92 & 82 & 94 & 91 & 89 & 91 & 102 & 81 & 82 & 92 & 94 & 94 & 83 & 92 & 92 & 89 & 93 & 93 & 83 & 82 & 82 & 92 \\
\hline $\mathbf{S}$ & 77 & 83 & 73 & 85 & 82 & 79 & 82 & 93 & 72 & 73 & 83 & 85 & 85 & 74 & 83 & 83 & 80 & 84 & 84 & 74 & 73 & 73 & 83 \\
\hline C & 88 & 94 & 84 & 96 & 93 & 90 & 93 & 104 & 83 & 84 & 94 & 95 & 95 & 85 & 94 & 94 & 90 & 95 & 95 & 85 & 84 & 84 & 94 \\
\hline 1 & 80 & 85 & 76 & 87 & 85 & 82 & 85 & 95 & 75 & 75 & 86 & 87 & 87 & 77 & 85 & 85 & 82 & 86 & 86 & 77 & 75 & 76 & 86 \\
\hline $\mathbf{r}$ & 89 & 95 & 85 & 97 & 94 & 91 & 94 & 105 & 84 & 85 & 95 & 97 & 97 & 86 & 95 & 95 & 92 & 96 & 96 & 86 & 85 & 85 & 95 \\
\hline
\end{tabular}

The duration data in Table 4 contain the effect of articulation on the duration of (o) in CVC combinations. The mean duration calculated from these data for (o) is $90 \mathrm{~ms}$. The minimal duration is $72 \mathrm{~ms}$, the maximum is $115 \mathrm{~ms}$. The distribution of duration values as a function of CVC combinations is shown in Table 5. The diverse duration values for (o) can be summarised into four $10 \mathrm{~ms}$ groups, i.e., CVC elements where the duration is between 70 and $79 \mathrm{~ms}, 80-89,90-99,100-109 \mathrm{~ms}$. The duration exceeds $110 \mathrm{~ms}$ only in the (ToT) combination. This distribution shows that the duration of (o) is the longest in the neighbourhood of palatals and it is the shortest in the neighbourhood of nasals and (S).

The summarised mean specific duration values of the 7 short and two long Hungarian vowels are given in Table 6 (page 334) and in Figure 2 (page 335). Vowel order data obtained with this inverse method correlate with earlier results of Kassai (1979) who gave the duration order of short vowels in accented position as: $[\mathrm{i}]<[\mathrm{u}]<[\mathrm{y}]<[\mathrm{o}]<[\varepsilon]<[\mathrm{\rho}]<[\varnothing]$ (where the ' $<$ ' sign means 'shorter than'). The present data give the same vowel order. 


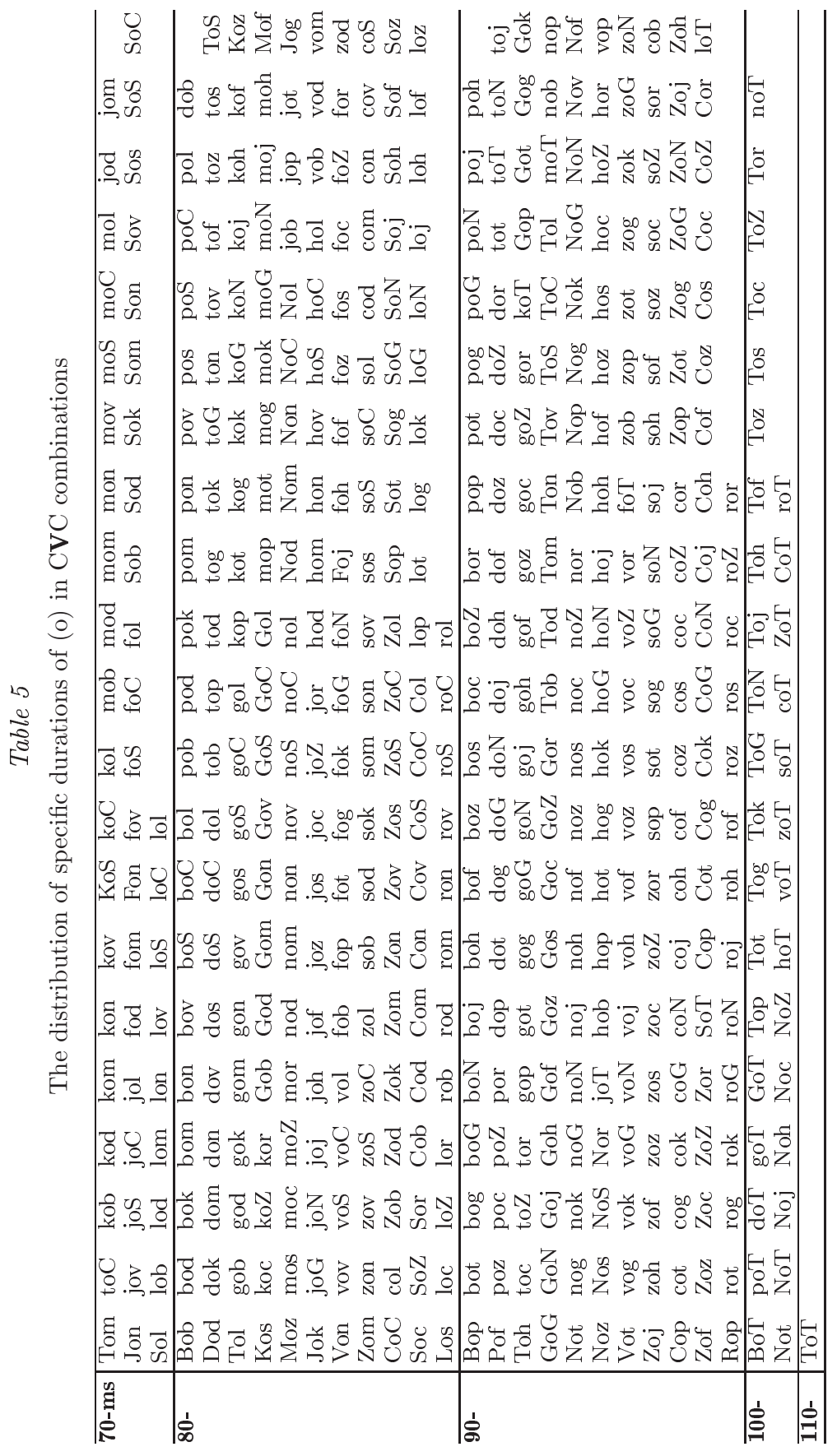

Acta Linguistica Hungarica 49, 2002 
As we look at the situation in other languages, similar results were reported by O'Shaughnessy (1981) for French vowels in closed syllables, where the shortest vowels were the high ones $[\mathrm{i}, \mathrm{u}]$, the mid vowel [e] was longer and the low vowel [a] was found to be the longest. Measured data for English (van Santen 1992) follow the same order both in stressed and in unstressed position. Thus the correlation between the duration and the height of the tongue during articulation is involved in our indirectly measured data as well.

For the two long vowels examined, our results also correlate with those of Kassai, i.e., the sound [e:] is shorter than [a:]. The distribution of short vowels ranges from $55 \mathrm{~ms}$ to $195 \mathrm{~ms}$ according to Kassai, the present results are 61-115 ms. The latter difference can be explained by the fact that Kassai measured the data from complex speech (with normal rhythm, accent, etc.), but now we derived them from a segmental level signal where the distribution is obviously narrower.

Table 6

Specific duration values determined for Hungarian vowels in ms for continuous speech

\begin{tabular}{|l|c|c|c|c|c|c|c|c|c|}
\hline vowel & $(\mathrm{i})[\mathrm{i}]$ & $(\mathrm{u})[\mathrm{u}]$ & $(\mathrm{U})[\mathrm{y}]$ & $(\mathrm{o})[\mathrm{o}]$ & $(\mathrm{a})[\mathrm{o}]$ & $(\mathrm{e})[\mathrm{\varepsilon}]$ & $(\mathrm{O})[\varnothing]$ & $(\mathrm{E})[\mathrm{e}:]$ & $(\mathrm{A})[\mathrm{a}:]$ \\
\hline \hline Mean & 80 & 86 & 86 & 90 & 91 & 91 & 92 & 146 & 164 \\
Min. & 61 & 69 & 61 & 72 & 73 & 64 & 71 & 124 & 128 \\
Max. & 99 & 113 & 103 & 115 & 113 & 115 & 109 & 170 & 196 \\
\hline
\end{tabular}

The average duration of all vowels is 102 ms. For English van Santen (1992) defines this value as $106 \mathrm{~ms}$. The average of all short vowels for Hungarian is $88 \mathrm{~ms}$, while van Santen gives the average duration data for English /i/ and $/ \Lambda /$ as 80 and $88 \mathrm{~ms}$, respectively. However, at some points the present results do not correlate with Kassai's measurements: we found that the duration of a vowel is not lengthened by the following (l), (r) sounds. Furthermore, our data do not support the finding that the duration of the vowel is consistently longer before voiced consonants than before voiceless ones.

\subsection{Consonants in $\mathrm{VCV}$ combinations}

For all consonants in all VCV combinations 1863 specific duration values were defined in 23 matrices. A sample matrix for the sound (b) is shown in Table 7 (page 336) where the duration values of (b) are given in milliseconds in all VCV combinations. The leftmost column of the matrix represents the preceding $\mathrm{V}$, the top row the following one. The target consonant (b) is shown at the upper left corner of the matrix.

Acta Linguistica Hungarica 49, 2002 

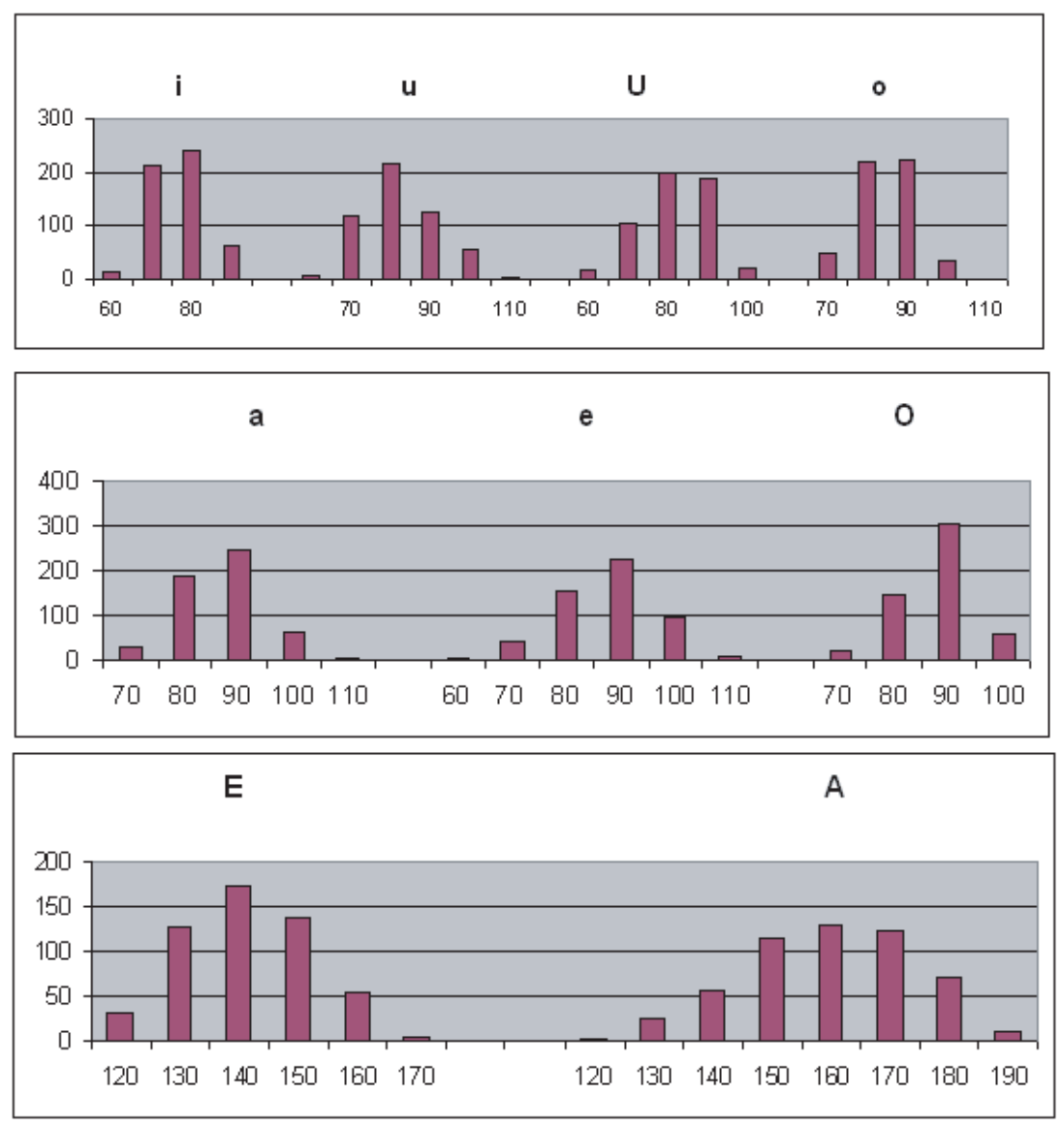

Fig. 2

The distribution of specific durations of Hungarian vowels in $\mathbf{C V C}$ combinations for continuous speech. The horizontal axis shows the duration data (in ms), the vertical axis shows the number of VCV items in which the given duration of the vowel occurs

For example, the specific duration of (b) in the sequence abe is shown at the cross-point of the row of (a) and the column of (e). The result is $62 \mathrm{~ms}$ for the given articulation rate. The minimum duration for (b) is $55 \mathrm{~ms}$, the maximum is $78 \mathrm{~ms}$. The duration distribution for (b) can be arranged into three $10 \mathrm{~ms}$ groups: 50-59, 60-69 and 70-79 ms. The majority of cases (55) are in the $60-69 \mathrm{~ms}$ area. The overall distribution for all stop consonants is shown in Figure 3 (overleaf). The horizontal axis shows the duration groups in milliseconds, the vertical axis shows the number of VCV items in which the 
Table 7

The specific durations for (b) in VCV combinations in $\mathrm{ms}$ for continuous speech

\begin{tabular}{|c|ccccccccc|}
\hline $\mathbf{b}$ & $\mathbf{A}$ & $\mathbf{a}$ & $\mathbf{o}$ & $\mathbf{u}$ & $\mathbf{U}$ & $\mathbf{i}$ & $\mathbf{E}$ & $\mathbf{0}$ & $\mathbf{e}$ \\
\hline $\mathbf{A}$ & 61 & 63 & 63 & 56 & 66 & 68 & 66 & 57 & 61 \\
$\mathbf{a}$ & 62 & 64 & 64 & 57 & 67 & 70 & 67 & 58 & 62 \\
$\mathbf{o}$ & 67 & 69 & 69 & 62 & 72 & 75 & 72 & 63 & 67 \\
$\mathbf{u}$ & 70 & 72 & 72 & 65 & 75 & 78 & 75 & 66 & 70 \\
$\mathbf{U}$ & 61 & 63 & 63 & 56 & 66 & 69 & 66 & 57 & 61 \\
$\mathbf{i}$ & 67 & 69 & 69 & 62 & 72 & 75 & 72 & 63 & 67 \\
$\mathbf{E}$ & 60 & 62 & 62 & 55 & 65 & 68 & 65 & 56 & 60 \\
$\mathbf{0}$ & 60 & 62 & 62 & 55 & 66 & 68 & 65 & 56 & 60 \\
$\mathbf{e}$ & 69 & 71 & 71 & 64 & 74 & 76 & 74 & 65 & 69 \\
\hline
\end{tabular}
b, p
d, $\mathbf{t}$
g. $k$
G, T

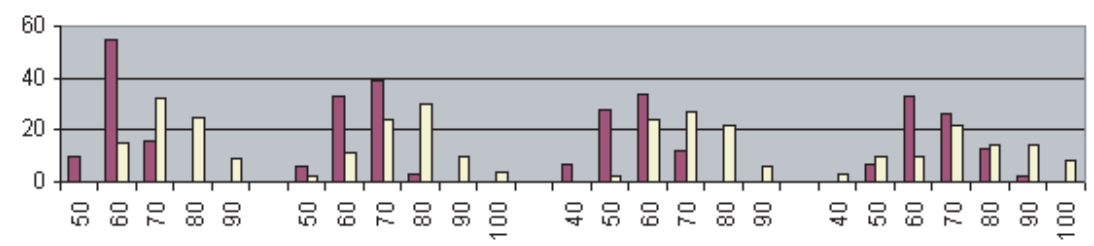

Fig. 3

The distribution of the specific duration of Hungarian voiceless stops (white) and voiced ones (dark) in VCV combinations for continuous speech

duration of the consonant occurs. The data show that voiceless stops (white) are longer than voiced ones (dark).

The distribution of voiceless stops shows a wider range than that of voiced ones. Comparing these data with the duration values of vowels in Figure 2, they show a wider distribution. Summarised values for all consonants are given in Table 8 in ms.

Comparing the results of Table 8 with the results of Kassai (1979) and Olaszy (1985), the order of the mean values of consonants coincides. Kassai gave the length order as: liquids $<$ nasals $<$ voiced stops $<$ voiced fricatives $<$ voiceless stops $<$ voiceless fricatives $<$ voiceless affricates. If we follow this order, the data from Olaszy (1985) are: 45, 67, 69, 65, 117, 120, $125 \mathrm{~ms}$, and the present data are: 44,61, 66, 65, 76, 79, $95 \mathrm{~ms}$. The difference between the data from 1985 and now can be explained with the material of the experiment. 
Table 8

The specific duration values in $\mathrm{ms}$ for consonants in VCV positions for continuous speech

\begin{tabular}{|l|c|c|c|c|c|c|c|c|}
\hline C & $(\mathrm{b})[\mathrm{b}]$ & $(\mathrm{p})[\mathrm{p}]$ & $(\mathrm{d})[\mathrm{d}]$ & $(\mathrm{t})[\mathrm{t}]$ & $(\mathrm{g})[\mathrm{g}]$ & $(\mathrm{k})[\mathrm{k}]$ & $(\mathrm{G})[\mathrm{f}]$ & $(\mathrm{T})[\mathrm{c}]$ \\
\hline \hline Mean & 65 & 77 & 70 & 76 & 62 & 74 & 68 & 76 \\
\hline Min. & 55 & 61 & 53 & 61 & 47 & 59 & 53 & 47 \\
\hline Max. & 78 & 94 & 80 & 96 & 78 & 92 & 87 & 88 \\
\hline \hline C & $(\mathrm{m})[\mathrm{m}]$ & $(\mathrm{n})[\mathrm{n}]$ & $(\mathrm{N})[\mathrm{n}]$ & $(\mathrm{j})[\mathrm{j}]$ & $(\mathrm{h})[\mathrm{h}]$ & $(\mathrm{v})[\mathrm{v}]$ & $(\mathrm{f})[\mathrm{f}]$ & $(\mathrm{z})[\mathrm{z}]$ \\
\hline \hline Mean & 67 & 48 & 66 & 59 & 62 & 61 & 85 & 68 \\
\hline Min. & 51 & 36 & 45 & 36 & 42 & 36 & 69 & 57 \\
\hline Max. & 82 & 64 & 88 & 102 & 82 & 76 & 96 & 76 \\
\hline
\end{tabular}

\begin{tabular}{|l|c|c|c|c|c|c|c|}
\hline $\mathrm{C}$ & $(\mathrm{s})[\mathrm{s}]$ & $(\mathrm{c})[\mathrm{ts}]$ & $(\mathrm{Z})[3]$ & $(\mathrm{S})[\mathrm{J}]$ & $(\mathrm{C})[\mathrm{f}]$ & $(\mathrm{l})[\mathrm{l}]$ & $(\mathrm{r})[\mathrm{r}]$ \\
\hline \hline Mean & 82 & 92 & 67 & 83 & 98 & 52 & 37 \\
\hline Min. & 62 & 77 & 46 & 76 & 77 & 37 & 18 \\
\hline Max. & 103 & 106 & 82 & 100 & 112 & 68 & 46 \\
\hline
\end{tabular}

Olaszy (1985) measured the data mainly in two-syllable words, the present data were defined for continuous speech.

The average duration for all consonants in VCV position ranges from $37 \mathrm{~ms}$ to $98 \mathrm{~ms}$.

\subsection{Consonants in $\mathrm{VCC}$ and $\mathrm{C} C \mathrm{~V}$ combinations}

Consonant clusters were examined only in VCC and in CCV combinations where the duration of the $\mathrm{C}$ in the middle position was defined. The results contain $2 \times 4761$ specific duration values for the 23 consonants for both types of combinations. The matrix for the sound (b) in VCC combinations is shown in Table 9. Table 10 shows the specific durations of (b) in CCV combinations.

Comparing the data with the durations of (b) in CVC combinations (Table 7) the conclusion is that the duration of (b) is longer in $\mathrm{VCC}$ and $\mathrm{CCV}$ combinations than in VCV position. The effect of articulation can be seen, for example, in the (m) column in Table 9, where the duration of (b) is shorter than in other columns. The same is the case in the $(\mathbf{m})$ row of Table 10. This shorter duration of (b) in the $(b)(m)$ and $(m)(b)$ combinations may be explained by the fact that (b) loses its burst in this VCC combination because of the identical bilabial articulation of the two consonants. In the CCV combination mentioned, the voiced stop portion of (b) is shorter because of 
Table 9

The specific durations for (b) in VCC combinations in ms, for continuous speech

\begin{tabular}{c|ccccccccccccccccccccccc}
$\mathbf{b}$ & $\mathbf{b}$ & $\mathbf{p}$ & $\mathbf{d}$ & $\mathbf{t}$ & $\mathbf{g}$ & $\mathbf{k}$ & $\mathrm{G}$ & $\mathrm{T}$ & $\mathbf{m}$ & $\mathbf{n}$ & $\mathbf{N}$ & $\mathbf{j}$ & $\mathbf{h}$ & $\mathbf{v}$ & $\mathbf{f}$ & $\mathbf{z}$ & $\mathbf{S}$ & $\mathbf{c}$ & $\mathbf{Z}$ & $\mathbf{S}$ & $\mathbf{C}$ & $\mathbf{1}$ & $\mathbf{r}$ \\
\hline $\mathbf{A}$ & 87 & 79 & 71 & 78 & 78 & 76 & 80 & 69 & 59 & 71 & 89 & 69 & 79 & 68 & 69 & 68 & 76 & 89 & 76 & 79 & 73 & 67 & 79 \\
$\mathbf{a}$ & 88 & 80 & 72 & 80 & 79 & 77 & 81 & 70 & 60 & 72 & 90 & 70 & 80 & 69 & 70 & 70 & 77 & 90 & 77 & 80 & 74 & 68 & 80 \\
$\mathbf{o}$ & 93 & 85 & 77 & 85 & 84 & 82 & 86 & 75 & 61 & 77 & 95 & 75 & 85 & 68 & 71 & 75 & 82 & 95 & 82 & 85 & 79 & 73 & 85 \\
$\mathbf{u}$ & 96 & 88 & 80 & 88 & 87 & 85 & 89 & 78 & 62 & 80 & 98 & 78 & 88 & 68 & 70 & 78 & 85 & 98 & 85 & 88 & 82 & 76 & 88 \\
$\mathbf{U}$ & 87 & 79 & 71 & 79 & 78 & 76 & 80 & 69 & 59 & 71 & 89 & 69 & 79 & 69 & 69 & 69 & 76 & 89 & 76 & 79 & 73 & 67 & 79 \\
$\mathbf{i}$ & 93 & 85 & 77 & 85 & 84 & 82 & 86 & 75 & 60 & 77 & 95 & 75 & 85 & 65 & 70 & 75 & 82 & 95 & 82 & 85 & 79 & 73 & 85 \\
$\mathbf{E}$ & 86 & 78 & 70 & 78 & 77 & 75 & 79 & 68 & 58 & 70 & 88 & 68 & 78 & 68 & 68 & 68 & 75 & 88 & 75 & 78 & 72 & 66 & 78 \\
$\mathbf{O}$ & 86 & 78 & 70 & 78 & 77 & 75 & 79 & 68 & 58 & 71 & 88 & 68 & 78 & 68 & 68 & 68 & 75 & 88 & 75 & 78 & 72 & 66 & 78 \\
$\mathbf{e}$ & 95 & 87 & 79 & 86 & 86 & 84 & 88 & 77 & 60 & 79 & 97 & 77 & 87 & 66 & 72 & 76 & 84 & 97 & 84 & 87 & 81 & 75 & 87 \\
\hline
\end{tabular}

the shared articulation point. Similar but not so strong reduction can be seen in the columns of (b)(v) and (b)(f) in Table 9.

In general, there is no significant difference between the durations of consonants in VCC and in $\mathrm{CCV}$ combinations.

Table 10

The specific durations for (b) in CCV combinations in ms, for continuous speech

\begin{tabular}{c|ccccccccc}
\hline $\mathbf{b}$ & $\mathbf{A}$ & $\mathbf{a}$ & $\mathbf{o}$ & $\mathbf{u}$ & $\mathbf{U}$ & $\mathbf{i}$ & $\mathbf{E}$ & $\mathbf{0}$ & $\mathbf{e}$ \\
$\mathbf{b}$ & 80 & 82 & 82 & 75 & 86 & 88 & 85 & 76 & 80 \\
$\mathbf{p}$ & 76 & 77 & 77 & 71 & 81 & 83 & 81 & 72 & 76 \\
$\mathbf{d}$ & 55 & 57 & 57 & 50 & 60 & 63 & 60 & 51 & 55 \\
$\mathbf{t}$ & 52 & 54 & 54 & 47 & 57 & 60 & 57 & 48 & 52 \\
$\mathbf{g}$ & 73 & 75 & 75 & 68 & 79 & 81 & 79 & 70 & 73 \\
$\mathbf{k}$ & 52 & 54 & 54 & 47 & 57 & 59 & 57 & 48 & 52 \\
$\mathbf{G}$ & 72 & 74 & 74 & 67 & 78 & 80 & 77 & 68 & 72 \\
$\mathbf{T}$ & 83 & 85 & 85 & 78 & 89 & 91 & 88 & 79 & 83 \\
$\mathbf{m}$ & 42 & 44 & 44 & 37 & 47 & 49 & 47 & 38 & 42 \\
$\mathbf{n}$ & 62 & 63 & 63 & 57 & 67 & 69 & 67 & 58 & 62 \\
$\mathbf{N}$ & 60 & 62 & 62 & 55 & 66 & 68 & 65 & 57 & 60 \\
$\mathbf{j}$ & 49 & 51 & 51 & 44 & 55 & 57 & 54 & 45 & 49 \\
$\mathbf{h}$ & 77 & 79 & 79 & 72 & 82 & 85 & 82 & 73 & 77 \\
$\mathbf{v}$ & 72 & 74 & 74 & 67 & 77 & 80 & 77 & 68 & 72 \\
$\mathbf{f}$ & 66 & 67 & 67 & 61 & 71 & 73 & 71 & 62 & 66 \\
$\mathbf{z}$ & 71 & 73 & 73 & 66 & 77 & 79 & 76 & 68 & 71 \\
$\mathbf{s}$ & 61 & 63 & 63 & 56 & 66 & 69 & 66 & 57 & 61 \\
$\mathbf{c}$ & 73 & 75 & 75 & 68 & 79 & 81 & 78 & 70 & 73 \\
$\mathbf{Z}$ & 75 & 77 & 77 & 70 & 80 & 83 & 80 & 71 & 75 \\
$\mathbf{S}$ & 76 & 77 & 77 & 71 & 81 & 83 & 81 & 72 & 76 \\
$\mathbf{C}$ & 62 & 64 & 64 & 58 & 68 & 70 & 68 & 59 & 62 \\
$\mathbf{1}$ & 60 & 62 & 62 & 55 & 65 & 68 & 65 & 56 & 60 \\
$\mathbf{r}$ & 87 & 89 & 89 & 82 & 93 & 95 & 92 & 83 & 87 \\
\hline
\end{tabular}

Acta Linguistica Hungarica 49, 2002 


\subsection{Comparisons with natural speech}

As it was seen, the results of the inverse measurement introduced gave relevant duration data. The defined specific duration values are characteristic of Hungarian continuous speech. Using these data the basic, segmental level duration of every sound in an utterance can be given. In Figure 4, the specific duration data and the measured ones of the beginning part of the sample

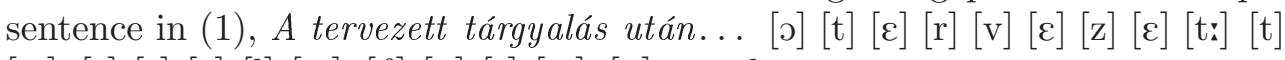
[a:] [r] [f] [o] [l] [a:] [J] [u] [t] [a:] [n] are shown.

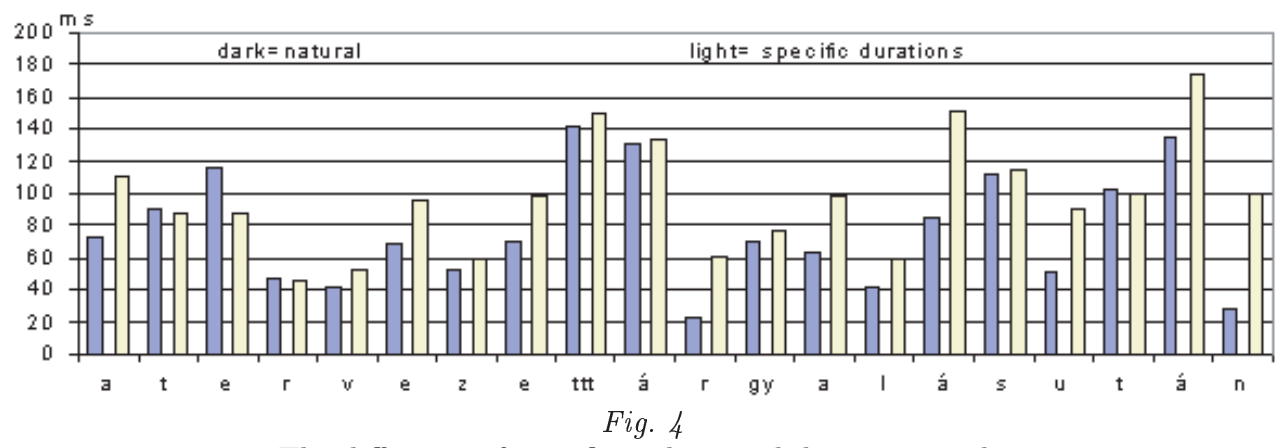

The difference of specific and natural durations in the first part of the sample sentence

The main tendency of the two representations is similar, the largest differences are in vowels. These differences will be eliminated by the suprasegmental level rules (2nd and 3rd step of the model).

\section{Suprasegmental level duration modification rules}

The second phase of the model contains 2 levels, word and phrase level modifications of the specific durations. The main goal here is to determine where and to what extent we should lengthen or shorten the specific duration of the given sound. The modification is performed in the model by using multiplying factors ranging for shortening between 0.5 and 0.95 , and for lengthening from 1.1 to 2 . A certain factor is determined for each sound of the utterance and applied on the specific durations of the sounds. Comparing the specific durations and the natural ones in the sample sentences and taking earlier results into consideration it was assumed that the further modification level is defined by the word. It was found that the length of the word and the inherent sound 
types and sound distributions influence the sound durations. The highest level modification (3rd part of the model) concerns the effects of phrase structure.

\subsection{Word level duration modifications}

At this level, the differences between natural and specific durations have been studied by making such duration pictures as was shown in Figure 4. It was found that in most cases the duration of vowels must be shortened, in some cases lengthened. 44 test sentences have been selected from the basic text material and these sentences were used for perceptual evaluation. The measurement setup for the test was basically the same as was shown in Figure 1. The only difference was that the test sentences were played with falling intonation (but without accent). Subjects had to compare two versions of the same sentence with two different duration structures. The first was produced with specific durations, the second with modified ones (using M1 factors and adjusting them to change the duration towards the natural values). The final M1 factors were determined from the results of these listening tests. The perceptual test showed that word level modifications are more important than those on the sentence level. After word level modifications, the duration structure of the utterance reached in most cases the stage of $90 \%$ of the final, desired one. Another conclusion was that accents do not influence the duration map of the word, i.e., no lengthening can be shown in most of the cases in accented vowels (accent is on the first syllable of the word in Hungarian). Similar results are reported by Fónagy (1958) and Kovács (2002). Strong accents (e.g., focus) may be exceptions.

It was found that two features define the duration modification on the word level: the sound map of the word and the length of the word. The sound map of the word shows the types of vowels, the consonant clusters, the place of sounds inside the word. Altogether twenty-five basic rules have been defined for the modification of short vowels. Examples are shown for the first short vowel of the word in Table 11. The data of this table show two things, i.e., the modifications are mostly shortenings, and the modification factors are vowel dependent. Separate rules (altogether 48) define the modification factors for long vowels. An example rule set is shown in Table 12 for the sound [a:]. Here separate rules define the modification as a function of the number of syllables in the word. The values of the modification factors express that the [a: $]$ is consistently shortened as a function of the number of syllables of the word. 
Table 11

Modifying multiplication factors for short vowels in the first syllable of a word longer than two syllables

\begin{tabular}{|c|c|c|c|c|c|c|c|}
\hline & \multicolumn{7}{|c|}{ VOWELS } \\
\hline SEQUENCE & (i) [i] & $(\mathrm{u})[\mathrm{u}]$ & $(\mathrm{U})[\mathrm{y}]$ & (o) $[\mathrm{o}]$ & (a) $[\mathrm{j}]$ & (e) $[\varepsilon]$ & $(\mathrm{O})[\varnothing]$ \\
\hline \# C V C1 & $\overline{1}$ & $\overline{0.8}$ & $\overline{0.8}$ & $\overline{0.8}$ & $\overline{0.8}$ & $\overline{0.8}$ & $\overline{0.8}$ \\
\hline \# C V C1 C & 1 & $\overline{1}$ & 1 & 1 & 1 & 0.8 & 1 \\
\hline \# C V C2 & 1 & 0.8 & 0.8 & 0.9 & 1 & 0.8 & 1 \\
\hline$\# \diamond \mathrm{C}$ V C1 & 0.8 & 0.8 & 0.8 & 1 & 0.9 & 0.9 & 0.8 \\
\hline$\# \diamond \mathrm{C} \mathrm{V} \mathrm{C1} \mathrm{C}$ & 1 & 1 & 0.8 & 1 & 1 & 0.9 & 1 \\
\hline$\# \diamond \mathrm{C} \mathrm{V} \mathrm{C2}$ & 0.8 & 0.8 & 0.8 & 1 & 1 & $\overline{0.9}$ & 1 \\
\hline$\# \mathrm{~V} \mathrm{C}$ & 0.8 & 0.8 & 0.8 & 1 & 0.9 & 1 & 1 \\
\hline \# V C1 C & 0.8 & 1 & 1 & 1 & 1 & 1 & 1 \\
\hline$\# \diamond \mathrm{VC}$ & 1 & 1 & 0.8 & 1 & 0.9 & 1 & 1 \\
\hline$\# \diamond \mathrm{V} \mathrm{C} 1 \mathrm{C}$ & 1 & 1 & & 1 & 1 & 1 & 1.1 \\
\hline \# V C2 C & 1 & 1 & 0.8 & 1 & 1 & 1.3 & 1 \\
\hline
\end{tabular}

$\mathrm{V}=$ the short vowel in question, $\mathrm{C}=$ any consonant, $\mathrm{C} 1=$ any consonant but not $[\mathrm{r}, \mathrm{l}], \mathrm{C} 2=[\mathrm{r}, \mathrm{l}], \diamond=$ article, \# = absolute initial position multiplication factor $=$ for example, 0.8

Table 12

Modifying multiplication factors for [a: if it is the only long vowel in the word (for 1, 2, 3, 4, 5 and 6-syllable words)

\begin{tabular}{|c|c|c|c|c|c|c|c|}
\hline & & \multicolumn{6}{|c|}{ SYLLABLE } \\
\hline [a: $]$ in the & SEQUENCE & 1 & 2 & 3 & 4 & 5 & 6 \\
\hline \multirow{2}{*}{ 1st syll. } & VC1 & - & 1 & 0.9 & 0.8 & 0.8 & 0.75 \\
\hline & VC2 & - & 1.3 & 1.2 & 1.2 & 1.1 & 1 \\
\hline \multirow{2}{*}{ 2nd syll. } & VC1 & - & - & 0.9 & 0.85 & 0.85 & 0.8 \\
\hline & VC2 & - & $=$ & 1 & 1 & 1 & 1 \\
\hline \multirow{2}{*}{ 3rd syll. } & VC1 & - & $\overline{-}$ & - & 0.9 & 0.8 & 0.8 \\
\hline & VC2 & - & - & - & 1 & 1 & 1 \\
\hline \multirow{2}{*}{$\begin{array}{l}\text { 4th and } \\
\text { later syll. }\end{array}$} & VC1 & - & - & - & - & 0.8 & 0.8 \\
\hline & VC2 & - & - & - & - & 1 & 1 \\
\hline \multirow{2}{*}{ Last syll. } & VC1 & 1.2 & 0.9 & 0.85 & 0.8 & 0.8 & 0.8 \\
\hline & VC2 & 1.3 & 1.3 & 1.3 & 1.2 & 1.1 & 1.1 \\
\hline
\end{tabular}

$\mathrm{V}=$ sound $[\mathrm{a}: \mathrm{i}, \mathrm{C} 1=$ any consonant but not $[\mathrm{r}, \mathrm{l}], \mathrm{C} 2=[\mathrm{r}, \mathrm{l}]$ multiplication factor $=$ for example, 1.3

The specific duration of consonants is modified by 8 rules like: shorten the specific duration of CC and CCC clusters if they are not in the last word of the sentence ([ng] and $[\mathrm{nk}]$ combinations are exceptions); shorten the specific duration of long stop consonants being at the end of the word (in sentence internal position). 
The difference in number of both rule groups shows that in continuous speech the duration of vowels varies more dynamically than that of the consonants. The result of word level modification is expressed in the model as follows: every sound of the word gets a multiplication factor. For example the duration map (the series of M1 factors) of the word latthatatlan $[1][\mathrm{a}:] \mathrm{t}][\mathrm{h}][\mathrm{o}][\mathrm{t}][\mathrm{o}][\mathrm{t}][\mathrm{l}][\mathrm{J}][\mathrm{n}]$ 'invisible' will show the following picture:

(2) $\quad$ l(1) a:(0.8) t(0.9) h(0.9) ว(0.9) t(1) ว(1) t(0.9) l(0.9) ว(1) n(1)

Comparative measurements have been performed between natural and synthesised durations at this level. It was found that $90 \%$ of the modelled durations was very close to the natural ones. Figure 5 shows again the duration map of the first part of the sample sentence in (1) after performing the duration modification on word level (according to step 2). It can be seen that the durations of vowels have been corrected towards the values of the natural sample. This result shows that sound durations in continuous speech are defined mostly by the specific durations and their modification on the word level (steps 1 and 2 in the model).

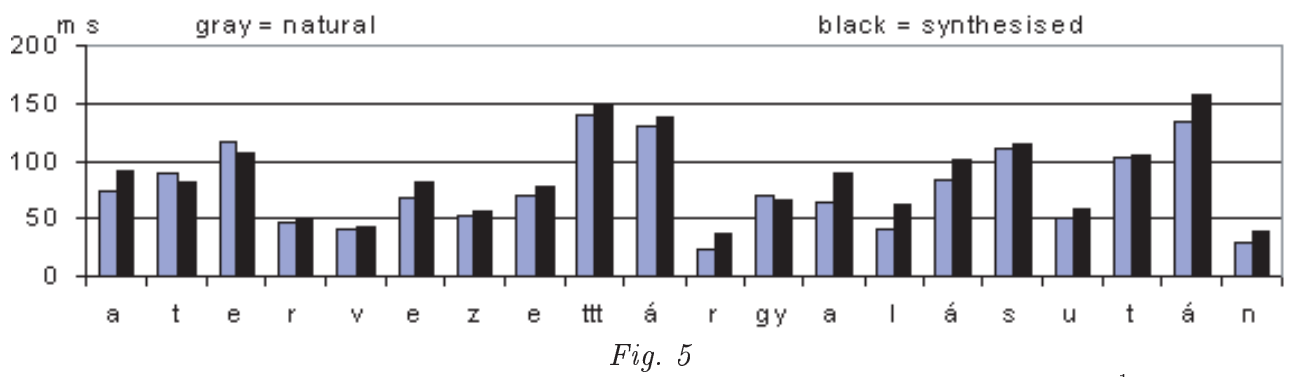

The corrected sound duration values of the sentence part of Figure $4 .{ }^{1}$

\subsection{Sentence level duration modification rules}

In the third step of the model only slight modifications are performed, mainly concerning lengthening: in the last word of the sentence and in the last syllable of the word at a phrase boundary and also in the first syllable of certain questions.

1 The horizontal axis contains the sounds represented orthographically. The articulation rate was 14 sounds/s in natural speech and 13 sounds/s in the synthesised one. Therefore most of the modelled durations are slightly longer than the natural ones. 


\section{Conclusions}

The proposed three-level model gives duration data very similar to natural pronunciation. The most important part of the model is the module of the first level, where the specific (segmental level) durations are determined. The indirect method for the definition of specific durations presented gives relevant data for the basic duration structure of the given language. Furthermore, this method gives us the possibility to define the only theoretically existing, segmental level specific sound durations in the form of exact data for every sound in every sound combination for the given language. The results for Hungarian showed that sound duration values defined with this inverse method correlate with the results of earlier investigations not only for Hungarian but also for English and French. This means that the inverse method presented can be successfully used for the definition of sound durations for continuous speech.

For Hungarian approximately 20,000 individual specific sound durations (in triphone sound sequences for the middle sound) have been determined.

Specific duration values can represent a good basis for further (suprasegmental level) duration modifications. The second step of the model represents a semi-suprasegmental level in which fine modifications of specific durations in the word are summarised. Rules can be determined at this level to characterise the value of shortening or lengthening of the sounds. Measurement results show that the sound durations in Hungarian are formed mostly on the segmental level and on the word level. Phrase and sentence level modifications have a less important role in forming final durations.

The advantage of this model can be summarised in five points:

1. The sound durations can be determined as a function of adjacent sounds for continuous speech (independently of the speaker or the type of text in question). The specific durations give a good basis for further studies about the organisation of the time structure of speech.

2. The influence of articulation on duration can be separated from other possible factors.

3. The results are recontrollable at any time.

4. The results show that sound durations are determined basically by the articulation and by the sound map of words in Hungarian. Phrase and sentence level influence on sound durations is small. 
5. The intrinsically existing specific durations are expressed by actual numerical values for the first time. They could not be derived till now on the basis of direct measurements.

\section{References}

Allen, Jonathan - Sharon Hunnicutt-Dennis H. Klatt 1987. From text to speech: the MITalk system. Cambridge University Press, Cambridge.

Campbell, Nick W. 1992. Syllable based segmental duration. In: G. Bailly-C. Benoît-T.R. Sawallis (eds) Talking machines: theories, models, and designs, 211-24. Elsevier Science Publishers, Amsterdam.

Fónagy, Iván 1958. A hangsúlyról [On accent]. Nyelvtudományi Értekezések 18. Akadémiai Kiadó, Budapest.

Huggins, A.W.F. 1972. Just noticeable differences for segment duration in natural speech. In: Journal of the Acoustic Society of America 51:1270-8.

Kassai, Ilona 1979. Időtartam és kvantitás a magyar nyelvben [Duration and quantity in Hungarian]. Nyelvtudományi Értekezések 102. Akadémiai Kiadó, Budapest.

Kato, H. - M. Tsuzaki-Y. Sagosaka 1998. Effects of phonetic quality and duration on perceptual acceptibility of temporal changes in speech. In: Proceedings of the 5th International Conference on Spoken Language Processing, 892-5. Sydney.

Kovács, Magdolna 2002. Tendenciák és szabályszerüségek a magánhangzó-időtartamok produkciójában és percepciójában [Tendencies and regularities in the production and perception of vowel durations]. Debreceni Egyetem, Debrecen.

Magdics, Klára 1966. A magyar beszédhangok időtartama [Duration of Hungarian speech sounds]. In: Nyelvtudományi Közlemények 68:125-39.

Olaszy, Gábor 1985. A magyar beszéd leggyakoribb hangsorépítő elemeinek szerkezete és szintézise [The structure and synthesis of the most important building elements of Hungarian speech]. Nyelvtudományi Értekezések 121. Akadémiai Kiadó, Budapest.

Olaszy, Gábor 1991. The inherent time structure of Hungarian speech sounds. In: Mária Gósy (ed.) Temporal factors in speech, 107-38. MTA Nyelvtudományi Intézet, Budapest.

Olaszy, Gábor-Géza Németh - Géza Kiss 2001. Hungarian audiovisual prosody composer and TTS development tool. In: Puppel Stanisław - Grażyna Demenko (eds) Prosody 2000, 167-78. Adam Mickiewicz University, Poznań.

Olaszy, Gábor - Péter Olaszi 1998. Hangidőtartamok mesterséges változtatása periódusok kivágásával, megismétlésével [Changing sound durations by inserting and deleting pitch periods]. In: Mária Gósy (ed.) Beszédkutatás 1998 [Speech research 1998], 151-62. MTA Nyelvtudományi Intézet, Budapest.

O'Shaughnessy, Douglas 1981. A study of French vowel and consonant durations. In: Journal of Phonetics $9: 385-406$.

Santen van, Jan P.H. 1992. Contextual effects on vowel duration. In: Speech Communication $11: 513-46$.

Santen van, Jan P.H. 1998. Timing. In: R. Sproat (ed.) Multilingual text-to-speech synthesis: the Bell Labs approach, 115-39. Kluwer, Dordrecht.

Acta Linguistica Hungarica 49, 2002 
Shiga, Y.-H. Matsuura-T. Nitta 1998. Segmental duration control based on an articulatory model. In: Proceedings of the 5th International Conference on Spoken Language Processing, 1244-7. Sydney.

Zellner, Brigitte 1994. Pauses and the temporal structure of speech. In: E. Keller (ed.) Fundamentals of speech synthesis and speech recognition, 42-62. John Wiley and Sons, New York.

Address of the author: Gábor Olaszy

Research Institute for Linguistics

Hungarian Academy of Sciences

Benczúr u. 33

H-1068 Budapest

olaszy@nytud.hu 